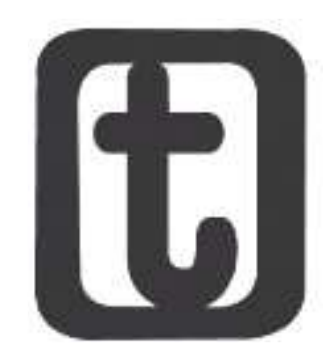

\title{
TEORIAS RACIAIS, LUTA DE CLASSES E IMPLEMENTAÇÃO DE POLÍTICAS PARA REPARAÇÃO: PERCURSO DO MOVIMENTO NEGRO NO BRASIL
}

\author{
Racial theories, class struggle and implementation of public policies for reparation: the \\ course of the Black Movement in Brazil
}

\author{
Jônatas Corrêa Nery* \\ Rogério Naques Faleiros**
}

\section{RESUMO}

Este trabalho trata sobre a trajetória histórica do Movimento Negro brasileiro, principalmente do século XIX ao XXI, e ao mesmo tempo apresenta a produção das teorias sobre a questão racial, produzidas de forma mais consolidada do final do século XIX à metade do XX. Busca-se apresentar a importância do Movimento Negro no processo histórico da luta de classes para a introdução de uma agenda de políticas públicas voltadas à população negra que de diversas formas resistiu às ameaças contra a sua liberdade e existência. Para tal realizou-se uma revisão de literatura sobre o tema a fim de articular história e teoria.

\section{PALAVRAS-CHAVE}

Movimento negro; Luta de classes; Teorias raciais.

\begin{abstract}
This work is about the historical trajectory of the Brazilian Black Movement, especially from the 19th to the 21st century, and at the same time presents the production of racial theories, produced in a more consolidated form from the late nineteenth century to the middle of the twentieth century. The aim is to present the importance of the Black Movement in the historical process of the class struggle for the introduction of an agenda of public policies aimed at the black population that in various ways resisted the threats against their freedom and existence. For this purpose, a literature review on the subject was carried out in order to articulate history and theory.
\end{abstract}

\section{KEYWORDS}

Black movement; Class struggle; Racial theories.

\footnotetext{
* Economista. Mestrando do Programa de Pós-graduação em Política Social (PPGPS), da Universidade Federal do Espírito Santo (UFES, Vitória. Brasil). Av. Fernando Ferrari, 514, Goiabeiras, Vitória (ES), CEP 29075-910. ORC ID: https://orcid.org/0000-0001-5355-6633. E-mail: jonatascorreanery@gmail.com.

** Historiador. Doutor em Economia Aplicada (área de concentração em História Econômica), pelo Instituto de Economia da Universidade Estadual de Campinas (Unicamp. Campinas. Brasil). Professor Associado I do Departamento de Economia da Universidade Federal do Espírito Santo (UFES) e do Programa de PósGraduação em Política Social. Av. Fernando Ferrari, 514, Goiabeiras, Vitória (ES), CEP 29075-910.ORC ID: <https://orcid.org/0000-0003-1209-8458>. E-mail:<naques@gmail.com>.
}

\section{DOI 10.22422/temporalis.2019v19n37p26-44}

\section{$(\mathrm{cc}) \mathrm{BY}$} (ntribuição 4.0 Internacional (https://creativecommons.org/licenses/by/4.0/deed.pt_BR), que permite copiar e redistribuir o material em qualquer suporte ou formato, bem como adaptar, transformar e criar a partir deste material para qualquer fim, mesmo que comercial. O licenciante não pode revogar estes direitos desde que você respeite os termos da licença.

Temporalis, Brasília (DF), ano 19, n. 37, p. 26-44, jan./jun. 2019. | ISSN 2238-1856 


\section{Introdução}

A história importa. E para Marx e Engels ${ }^{1}$ a história da humanidade é a própria materialização da luta de classes. A primeira afirmação do parágrafo parece óbvia, mas não é assim tão simples. A segunda, fundamentada nos socialistas, ainda muito menos. E, embora alguns abram mão desse tipo de compreensão da realidade, é sob esse escopo, de análise sócio-histórica e também teórica, que situa esta leitura sobre a trajetória do Movimento Negro brasileiro. A luta dos afrodescendentes nesse país começou logo ao desembarque nos diversos portos da costa brasileira ainda colonial. Ela se desenvolveu e se configurou de diversas maneiras dentro desse país: criando organizações territoriais desligadas dos domínios senhoriais; revoltas e assassinatos de senhores; queima das plantações; embriaguez; suicídio; insurreições; movimentos negros sociais civis organizados e muitas outras formas de resistência.

Por isso, compreendendo a importância desses movimentos de resistência, esse trabalho buscará, por determinado recorte histórico, mas sem perder a perspectiva de totalidade, apresentar a trajetória do movimento negro brasileiro, passando por uma análise das leituras teórico-científicas sobre a questão racial ${ }^{2}$ no Brasil, na busca de ressaltar a importância dos movimentos sociais civis negros organizados, bem com a de alguns intelectuais, para incluir na agenda oficial, políticas de ação afirmativa voltadas para a população negra desse país. Essa empreitada terá um enfoque principal no período pós 1888, avançando até o século XXI.

Ao longo da história das pessoas negras no Brasil, sempre houve resistência. Mas elas se destacaram no pós-libertação oficial, em 1888. Surgiram muitas organizações para lutar contra o racismo que se materializava de diversas formas, científica ou por meio de políticas públicas, como foi o caso da imigração para o branqueamento, que se baseou na eugenia e no darwinismo social.

Posterior a essas leituras surgiu uma calcada na cultura. Seu principal expoente foi Gilberto Freyre. Baseado no mito das três raças e na ideia do mestiço como a solução das relações senhor/escravo, consolidou em sua obra o que posteriormente foi tratado como Democracia Racial. Essa compreensão só foi revista criticamente na década de 1950, por Florestan Fernandes.

Florestan Fernandes, na década de 1950, rompe com as leituras anteriores e passa a apresentar o negro como sujeito histórico e que a questão racial o afligia diretamente. Visão que corroborava com o Movimento Negro e por isso escreveu em articulação com ele. Esse entrelaçamento resulta mais tarde, na década de 1970, no Movimento Negro

\footnotetext{
${ }^{1}$ MARX, Karl; ENGELS, Friedrich. Manifesto do partido comunista. São Paulo: Edipro, 1998. 112p.

2 O termo raça repetidamente se remeterá intencionalmente à ideia de raça, pois, como aponta Maio e Santos (1994, p. 173) “[...] [ele] não se esgota no domínio das ciências biológicas, possivelmente daí derivando sua persistência e dos significados a ele associados através dos tempos". Portanto, "[...] Raça é [...] um artefato histórico e social, isso sem negar que o mesmo conceito esteja se transformando em princípio condutor da formação de categorias e grupos sociais significativos" (SHWARCZ, 2006, p. 289). Em outras palavras, para Munanga (2010, p. 8), “[...] raça apresentada sempre como uma categoria biológica natural é na realidade uma categoria político-ideológica”. Assim, a utilização do termo não mascara, nessa compreensão, seus desígnios históricos, impedindo que se esqueça de qual fora a utilização dele pela sociedade brasileira, obrigando, sempre que utilizado, a uma reflexão crítica sobre o passado desse país.
}

Temporalis, Brasília (DF), ano 19, n. 37, p. 26-44, jan./jun. 2019. | ISSN 2238-1856 


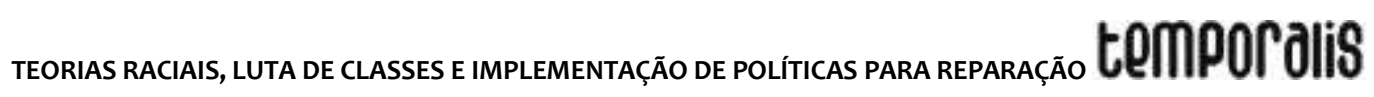

Unificado (MNU). Movimento Negro de esquerda que passa a pautar a agenda oficial do Estado. Culminando adiante em algumas políticas específicas para a população negra.

Assim, com a intenção de relacionar história, teoria, e apresentar a dinâmica da luta de classes, o presente trabalho contará com essa introdução, seguirá a uma apresentação sobre a trajetória do movimento negro no Brasil, passará por um resgate das teorias racialistas que foram fecundas nesse país e pela posterior ruptura protagonizada por Florestan Fernandes, culminando com a introdução na agenda nacional de algumas políticas para a população negra. Por fim, uma breve conclusão.

\section{Movimento Negro brasileiro}

A história da pessoa negra no Brasil, desde a sua chegada forçada a essa terra, é de luta e de resistência. Foram várias as formas de combater as agruras funestas da escravização: resistências individuais e também coletivas. Como já se apontou na introdução o suicídio dos escravizados foi uma forma de fugir ao cativeiro (ODA, 2008); os furtos e a embriagues constantes, também estiveram dentre os artifícios da desobediência (SIMAS, 2014); junto a estas estavam também a organização de levantes pequenos que culminavam no assassinato de senhores e feitores, mas que dado o caráter revolto espontâneo, portanto, pouco organizado, acabavam se entregando à autoridade local (REIS, 2000); existiram também a organização dos quilombos, que foram organizações de ajuntamento de pessoas negras fugidas. Dentre elas, a mais significativa foi o Quilombo de Palmares. Essa foi a maior e mais importante organização negra para fugir do domínio da escravização no mundo, como indica Marquese (2006).

Essas formas de luta e de resistência indicam um constante movimento dos sujeitos que estavam sob o jugo da escravização. As pessoas negras escravizadas dentro do sistema de castas que existia no Brasil, que começa no período colonial e se estende por todo o império, estiveram constantemente em movimento de resistência, contudo, embora “[...] onde quer que a escravidão existisse, o negro marron, o quilombola, portanto, aparecia como um sinal de rebeldia permanente contra o sistema que o escravizava [...]" (MOURA, 1989, p. 11), os contornos modernos da resistência, no que tange aos movimentos sociais civis organizados, só passam a ganhar forma e força após a libertação formal, em 1888, relacionando-se com a própria natureza do sistema que estava se consolidando. Portanto, Quilombos existiram durante todo o período nos quais as pessoas negras estiveram sob o jugo legal da escravização. Palmares foi um caso emblemático que em muito representava a forma, força e capacidade das pessoas negras de se organizarem contra o sistema escravista. Assim, valida Moura (1989) indicando que "Palmares foi a maior manifestação de rebeldia contra o escravismo na América Latina. Durou quase cem anos e, durante esse período, desestabilizou regionalmente o sistema escravocrata" (MOURA, 1989, p. 38). Mas é evidente que um Quilombo que pode ser tratado como república de homens livres, como ilustra Moura (1989) em um título de capítulo, justifica-se pelas condições sócio-históricas específicas reunidas que possibilitaram aquele agrupamento, como trata Oda (2008).

Contudo, foi logo após a libertação formal e a percepção da população negra de que a libertação jurídica não lhes trouxera ganhos objetivos significativos para mudar sua condição de vida, que começam a formarem espaços de mobilização racial no Brasil, tais

Temporalis, Brasília (DF), ano 19, n. 37, p. 26-44, jan./jun. 2019. | ISSN 2238-1856 
como clubes, grêmios e/ou associações, em muitos estados. Domingues (2007, p. 103) indica que em São Paulo

[...] apareceram o Clube 13 de Maio dos Homens Pretos (1902), o Centro Literário dos Homens de Cor (1903), a Sociedade Propugnadora 13 de Maio (1906), o Centro Cultural Henrique Dias (1908), a Sociedade União Cívica dos Homens de Cor (1915), a Associação Protetora dos Brasileiros Pretos (1917); no Rio de Janeiro, o Centro da Federação dos Homens de Cor; em Pelotas/RG, a Sociedade Progresso da Raça Africana (1891); em Lages/SC, o Centro Cívico Cruz e Souza (1918). Em São Paulo, a agremiação negra mais antiga desse período foi o Clube 28 de Setembro, constituído em 1897. As maiores delas foram o Grupo Dramático e Recreativo Kosmos e o Centro Cívico Palmares, fundados em 1908 e 1926, respectivamente (DOMINGUES, 2007, p. 103).

Essas entidades tinham cunho assistencialista, recreativo ou cultural. As associações conseguiram aglutinar um número expressivo de pessoas negras, pois se organizavam em torno de categoria de trabalhadores, tais como ensacadores, ferroviários, portuários, dentre outros, o que as fez ter um caráter próximo ao de um sindicato (CUNHA JÚNIOR, 1992). Essas organizações surgiram em grande escala, tanto que Pinto (1993) fala do registro de 123 associações de pessoas negras em São Paulo, entre os anos de 1907 e de 1937. Enquanto Muller (1999), citada por Domingues (2007), verifica a criação de 72 associações, na cidade de Porto Alegre, entre os anos de 1889 e de 1920 . E por fim, para se ter ideia do tamanho desse movimento, em Pelotas-RS, percebeu-se 53 dessas organizações, entre os 1888-1929 (MULLER, 1999). Domingues indica ainda que existiram nesse período diversas associações que foram estruturadas exclusivamente por mulheres negras, dentre as quais destaca a Sociedade Brinco das Princesas (1925), de São Paulo, e a Sociedade de Socorros Mútuos Princesa do Sul (1928), de Pelotas.

Concomitante a toda essa movimentação, organização e luta por melhores condições de vida da população negra, pois era disso que tratavam essas organizações, ainda de forma que não se questionasse o modelo econômico vigente, como aponta Florestan (2008), surge a Imprensa Negra.

Foram fundados vários veículos de comunicação que objetivaram tratar de questões que a população negra demandava. Esses jornais, portanto, foram fundados na perspectiva de luta contra o preconceito de cor. E não foram poucos,

Em São Paulo, o primeiro desses jornais foi A Pátria, de 1899, tendo como subtítulo Orgão dos Homens de Cor. Outros títulos também foram publicados nessa cidade: O Combate, em 1912; O Menelick, em 1915; O Bandeirante, em 1918; O Alfinete, em 1918; A Liberdade, em 1918; e A Sentinela, em 1920. No município de Campinas, O Baluarte, em 1903, e O Getulino, em 1923. Um dos principais jornais desse período foi o Clarim da Alvorada, lançado em 1924, sob a direção de José Correia Leite e Jayme Aguiar. Até 1930, contabiliza-se a existência de, pelo menos, 31 desses jornais circulando em São Paulo (DOMINGUES, 2007, p. 104).

Além desses surgiram também em outros estados veículos com o mesmo caráter, “[...] como a Raça (1935), em Uberlândia (MG), o União (1918), em Curitiba (PR), O Exemplo (1892), em Porto Alegre (RS), e o Alvorada, em Pelotas (RS)" (DOMINGUES, 2007, p. 105). Sendo o último o mais longevo, com término em 1965. 


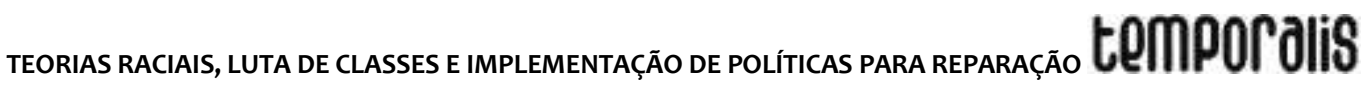

Com o objetivo bem definido a Imprensa Negra tratava as mais diversas temáticas que perpassavam a vida da população negra. Falavam da moradia, do trabalho, da saúde e da educação. Esses jornais se tornaram púlpitos contra o preconceito de cor, denunciando as mais variadas formas de segregação sofrida pelas pessoas negras em diversas partes, levando a público o que se mantivera velada: a segregação racial. Ou seja, denunciava aquilo que não estava posto explicitamente nas leis, mas que se constituíra prática corriqueira no Brasil: o impedimento de acesso das pessoas negras a determinados hotéis, a clubes, a associações, a cinemas, a teatros, a estabelecimentos comerciais, a instituições religiosas e até a orfanatos (DOMINGUES, 2007). Contudo, embora esse instrumento tenha se colocado, pela população negra, e para ela, como artefato político, de denúncia e de reinvindicação, não o fez, tal como aqueles das associações, dos clubes e dos grêmios, de forma a questionar a própria estrutura societária vigente. Isso não reduz evidentemente de forma nenhuma a importância desses movimentos/organizações dentro daquele contexto histórico. Mas foi, principalmente, a partir da década de 1930, que o Movimento Negro toma uma forma política mais relevante em termos de organização, entretanto, ao mesmo tempo em que o MN ganha relevo e expressão política, apresenta uma postura ideológica conservadora ${ }^{3}$, de direita (DOMINGUES, 2007). Esse salto qualitativo e organizativo do MN aconteceu com a fundação da Frente Negra Brasileira (FNB), em 1931 (OLIVEIRA, 2002; DOMINGUES, 2008).

A FNB foi criada em 1931, em São Paulo, como um movimento que tinha na sua estrutura reivindicações políticas nitidamente traçadas. Ela conseguiu milhares de filiados Brasil afora, instalando filiais nos estados do Rio de Janeiro, de Minas Gerais, do Espírito Santo, de Pernambuco, da Bahia e do Rio Grande do Sul, e conseguiu com isso tornar a entidade em um movimento de massa. Com sua forte estrutura organizativa, que contava com manutenção de escolas, grupo musical e teatral, departamento jurídico, time de futebol, cursos para formação política, para formação de artes e ofícios e mesmo um jornal, A Voz da Raça, lançou-se partido em 1936 e pretendia disputar as eleições de 1937. A intenção era a de disputar os votos da população de cor, como tratavam à época (OLIVEIRA, 2002; DOMINGUES, 2007).

Um dado significativo acerca da FNB é o fato dessa organização ter alcançado um tamanho pouco comum à época, principalmente enquanto partido com expressão nacional, em 1936 (OLIVEIRA, 2002) e ser, ao mesmo tempo, que a representação nacional da população negra, uma vigorosa opositora do comunismo, chegando a defender explicitamente os regimes autoritários de Mussolini e Hitler (DOMINGUES, 2007; OLIVEIRA, 2002). Esse elemento é importante para se compreender que essa organização embora tivesse uma bandeira política definida e alinhada com a questão racial, ela buscava principalmente um processo integrador, não crítico ao modelo econômico e político vigente. Cabe ressaltar que a FNB era a maior organização de pessoas negras no país, contudo, não era a única. Inclusive existiam outras com perspectivas ideológicas bem divergentes das dela.

A FNB, bem como os diversos movimentos contestatórios no país, perdeu força com a ditadura de 1937, e foi extinta. O governo varguista, o Estado Novo, como ficou conhecido, caracterizou-se como centralizador, nacionalista, anticomunista e fortemente autoritário.

\footnotetext{
3 Apesar das importantes denúncias contra o preconceito racial sofrido pela população, esse movimento teve forte ligação com bandeiras ideológicas nazifascistas.
}

Temporalis, Brasília (DF), ano 19, n. 37, p. 26-44, jan./jun. 2019. | ISSN 2238-1856 
Devido a esse perfil os movimentos sociais perderam significativamente seu poder de mobilização. Essa situação só foi mudada com o fim desse período, 1937 - 1945.

Do final do Estado Novo até a ditadura civil militar de 1964, o Movimento Negro ganhou novo perfil, mas perdeu a característica de movimento de massa que possuía (DOMINGUES, 2007). Entretanto isso não impediu que fossem criadas grandes organizações raciais com relativa importância política. Dentre elas, Domingues (2007) indica a União dos Homens de Cor (UHC), além do Teatro Experimental do Negro (TEN).

A UHC, fundada em 1943, foi um movimento que atingiu significativo grau de complexidade organizativa, conseguiu se desenvolver em nível nacional, em vários estados, e teve um direcionamento de contribuir para o desenvolvimento econômico e intelectual de todas as pessoas de cor, com vistas a integrá-las na vida social e administrativa do país, como ressalta Domingues (2007). Foi possível notar seu crescimento e relevância diante do rápido espraiamento país afora via estabelecimento de unidades locais, em estados como Espírito Santo, Paraná, Minas Gerais, Bahia, Ceará, Rio Grande do Sul, Maranhão, São Paulo, Piauí e Santa Catarina. De uma forma geral, sua frente de ação consistia na "[...] promoção de debates na imprensa local, publicação de jornais próprios, serviços de assistência jurídica e médica, aulas de alfabetização, ações de voluntariado e participação em campanhas eleitorais" (DOMINGUES, 2007, p. 108). Sua atividade política obteve resultados, conseguiram eleger José Bernardo da Silva como deputado federal por dois mandatos consecutivos; também conseguiram reunião com o então presidente Getúlio Vargas, em 1950, apresentando-lhe uma série de reivindicações de políticas a favor das pessoas negras (DOMINGUES, 2007).

Concomitante à UHC surgiu o TEN, em 1944, no Rio de Janeiro. Esse movimento tinha como proposta inicial ser formado apenas por pessoas negras. A ideia era ser um grupo teatral, mas suas atividades foram aos poucos se ampliando. Fundaram um jornal (Quilombo), grupos de alfabetização, cursos de corte e costura, fundou o Instituto Nacional do Negro, fundou o Museu do Negro, realizou um concurso de artes plásticas, com grande repercussão nacional, que tinha como tema o Cristo Negro. Abdias do Nascimento foi a principal liderança do TEN, ele se destacava pela sua atuação política e também como intelectual. Defendeu de forma contundente a criação de leis antidiscriminatórias como forma de efetivação dos direitos humanos para a pessoa negra. Contudo, naquele período esse debate foi fortemente oposto pelos defensores da democracia racial.

Por fim, cabe ressaltar que a UHC e o TEN, não foram os únicos movimentos em prol das pessoas negras nesse período, mas certamente os mais expressivos nacionalmente. Porém, eles e as demais organizações sofreram refluxo, e mais uma vez por causa de uma ditadura, agora a de 1964. Dessa forma foi interrompida uma fase da formação social brasileira, onde os movimentos sociais, como um todo, começavam a pautar a política nacional, em uma arquitetura não revolucionária, mas que em alguma medida mexia com as estruturas sociais e políticas do país ${ }^{4}$.

Em resumo, é preciso ter em tela o que foi apresentado até aqui, genericamente: os movimentos de resistência negra. No início, ainda no período da escravização, eles não devem ser tratados como movimentos sociais civis organizados, pois tem um caráter ainda

\footnotetext{
${ }^{4}$ É possível encontrar referência a esse debate em Netto (2007).
} 


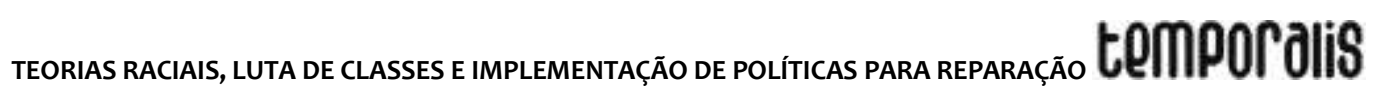

diminuto, aparecendo em muitas ocasiões como ações individuais e/ou de pequenos grupos 5 . Só após a escravização formal ter acabado é que surgem diversas organizações que tem como pauta política a melhoria das condições de vida da pessoa de cor, como tratavam.

Esses movimentos de pessoas negras, pós-escravização (jornais, clubes, associações, agrupamentos etc. $)^{6}$, surgem como reação àquilo que Ihes era mais sensível: a condição de vida degradante, e de abandono, à qual foram expostas depois de $1888^{7}$. E para eles, o passado de escravização dava substância explicativa àquela realidade, mas não era o suficiente; o preconceito de cor, somado à /escravidão é que poderia explicar melhor, para eles, a condição socioeconômica em que viviam. Portanto, esses movimentos tinham substancial compreensão do que lhes afligia, ou seja, não atribuíam exclusivamente ao seu passado a condição de vida que experimentavam naquele momento, contudo, não conseguiram vislumbrar, ainda, saída para além do modelo econômico vigente. Seus reclames de luta estavam dentro do escopo da sociedade capitalista emergente.

\section{0 pensamento racialista no Brasil e a quebra de paradigma}

A questão da miscigenação no Brasil é antiga e esteve presente na maioria dos escritos que discutiram a formação social brasileira. Não à toa essa (a miscigenação) tem sido considerada a válvula de escape, a chave explicativa para o problema racial no Brasil (SEYFERTH, 1989). Contudo, o mestiço, nas suas mais variadas nomenclaturas, não aparece de forma unívoca nesses trabalhos. Ora é tratado como problema, noutra como solução para o país. Essa indefinição e ambiguidade de tratamento se relaciona diretamente com o receio das elites brasileiras no que concernia ao fim da escravização. Sim, pois, essa já estava a ser questionada há muito e no século XIX a questão se torna pungente. Nesse sentido, a questão racial, portanto, precede às “[...] Ciências Sociais no Brasil” (SEYFERTH, 1989, p.11).

Esse debate inicia no Brasil “[...] a partir de 1870 [quando] introduzem-se no cenário brasileiro teorias de pensamento até então desconhecidas, como o positivismo, o evolucionismo, o darwinismo" (SCHWARCS, 2017 [1993], p. 57). Existia uma questão de fundo que era a escravidão como um problema a ser superado. Neste caso a preocupação girava em torno das consequências da manutenção do regime ao mesmo tempo que com o receio do seu fim (SEYFERTH, 1989). A compreensão era a de que essa instituição (a escravidão) fazia parte de uma estrutura arcaica que não era mais compatível com o desenvolvimento econômico e social do país, pois impedia a vinda de imigrantes europeus, sujeitos da civilização, ao mesmo tempo em que enchia o país de negros africanos. $O$ debate pelo fim da escravidão passava, portanto, pela preocupação sobre as consequências funestas que ela poderia causar à sociedade. Veja-se, com isso, que, por parte da elite brasileira e até dos abolicionistas, não existiu preocupação sobre a transformação da pessoa negra (escravizada) em cidadão livre, ao contrário, evoca-se a substituição desse pelo imigrante branco, “[...] o trabalhador livre por excelência".

\footnotetext{
${ }^{5}$ Cabe sempre a ressalva da experiência de Palmares.

${ }^{6}$ Ressalta-se que o período tratado foi do colonial/imperial brasileiro, focando principalmente o póslibertação, 1888, formal até a ditadura de 1964.

7 É possível encontrar mais conteúdo sobre esse debate em Fernandes (2008).
}

Temporalis, Brasília (DF), ano 19, n. 37, p. 26-44, jan./jun. 2019. | ISSN 2238-1856 
(SEYFERTH, 1989, p.12). A questão, portanto, passava mais pelo viés de como seria o pósescravidão, que propriamente por um discurso eminentemente racista, como aponta Seyferth (1989).

Nesse período começa haver relativa confusão quanto ao que fazer com a questão racial. Foi então que essa questão surge, e como resultado do esgotamento de um modelo econômico que já não respondia às demandas e aos anseios das potencias capitalistas, principalmente aos da Inglaterra. Nesse momento o receio era de que o Brasil pudesse se tornar um novo Haiti ${ }^{8}$; existia um temor quanto ao que as pessoas negras (escravizadas) poderiam fazer contra os senhores; ao mesmo tempo, os abolicionistas entendiam que não existia preconceito racial no Brasil, portanto, a libertação pura e simples resolveria a questão do negro, pois a miscigenação resolveu o problema no Brasil. Portanto, para solucionar definitivamente o caso se deveria exacerbar o processo de imigração dos brancos europeus. Dessa forma se eliminaria o negro via assimilação.

Sylvio Romero (2001) é apontado como o primeiro ensaísta a discutir a tese do branqueamento no Brasil. Esse autor foi influenciado de forma significativa pela compreensão europeia, segundo Seyferth (1989) e Santos (2014), que, por sua fez, afirmam eles, baseou sua obra nas compreensões, principalmente, em Gobineau, Haeckel, Le Play, Spencer, além de alguns outros autores influenciados pelas ideias evolucionistas do período. A ideia nesse autor era a de que, no caso do Brasil, o processo de imigração eliminaria a raça negra porque a branca era superior, mais forte e mais apta. Conclui: "[...] à medida, porém, que a ação direta das duas últimas tende a diminuir, com a internação do selvagem e a extinção do tráfico dos pretos, a influência européia tende a crescer com a imigração e pela natural propensão para prevalecer o mais forte e o mais hábil" (ROMERO, 2001, p. 35).

Essa noção, baseada no biológico, de que a raça negra era invariavelmente inferior à branca foi fortemente disseminada. Tanto que esteve como produção sensível em obras como Os Sertões, de Euclides da Cunha. Nela, por exemplo, o mestiço é elogiado por ser fruto do cruzamento do índio com o bandeirante branco paulista, mas logo depois é apresentado como decadente e inferior; se distanciava, pois, da civilização. Nesse sentido é possível dizer que a teoria do branqueamento se estruturou sobre uma utopia, pois, uma vez aceita a ideia de que a raça branca ariana era quem possuía todos os requisitos para o desenvolvimento, o Brasil estaria fadado ao fracasso. Contudo, encontrou no darwinismo social e na teoria de Gobineau a possibilidade da preponderância de um povo branco sobre as demais raças inferiores (SANTOS, 2014; SEYFERTH, 1989).

Foi então quando a tese de João Baptista de Lacerda, em 1911, ganha destaque internacional no Congresso Universal das Raças, em Londres. Nesse evento Lacerda participava como representante do Brasil. Ele apresentava nessa ocasião a miscigenação como solução brasileira para o problema racial. Nessa teoria não há menção formal sobre a desigualdade das raças, mas, indica implicitamente que as pessoas negras são inferiores. Além disso, nesse evento Lacerda, divergindo de Sylvio Romero, indica com certo otimismo que em 100 anos, devido à imigração europeia branca, as pessoas negras, indígenas e outras raças desapareceriam. A compreensão acerca das raças, apresentada por esses

\footnotetext{
${ }^{8}$ É possível encontrar várias referências que apontam para o temor da elite branca brasileira sobre esse fator, dentre elas, a título de informação Nascimento (2008).
}

Temporalis, Brasília (DF), ano 19, n. 37, p. 26-44, jan./jun. 2019. | ISSN 2238-1856 


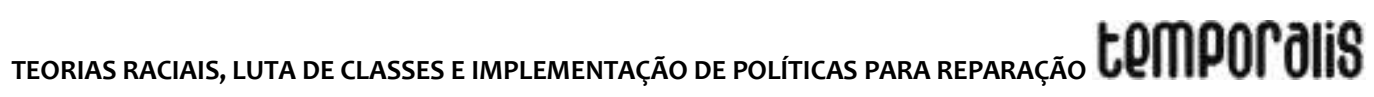

autores, indica visivelmente o racismo, contudo, mesmo diante do exposto é possível dizer que eles não adotaram com afinco as teorias racialistas calcada no biológico (SANTOS, 2014; SEYFERTH, 1989).

O mesmo não se pode dizer de Oliveira Vianna, que "[...] construiu uma obra situada na área da Sociologia e da Psicologia Social, totalmente identificada com o darwinismo social e com as propostas que se coadunavam com o fascismo". (SEYFERTH, 1989). A mesma Seyferth indica que Vianna propõe um exercício do poder feito pelos arianos autoritariamente com vistas a se chegar a uma raça totalmente branca. O mito ariano fora tão convincente para ele que encontrou no Brasil uma aristocracia rural ariana que, por sua vez teria salvado o Brasil de uma suposta inferioridade racial.

Próximo ao pensamento de Vianna estava o do Raimundo Nina Rodrigues (SANTOS, 2014; SEYFERTH, 1989). Como é possível ver em Bahia, Menasche e Zanini (2015), grande parte da obra do Nina Rodrigues foi datada da década de 1890, mas ela foi reverberada por seus discípulos Arthur Ramos e Édison Carneiro, como a fundadora dos estudos sobre a pessoa negra no Brasil e a fundadora da escola antropológica na Bahia (SEYFERTH, 1989).

Contraditoriamente, Nina Rodrigues, embora muito enaltecido por antropólogos eminentemente racistas, teve de fato contribuição significativa nos estudos das religiões de matriz africanas, contudo, sua análise sobre a questão racial, afora aquela parte, foi calcada pelo determinismo racial de forma tão acentuada (BAHIA; MENASCHE; ZANINI, 2015) que o colocou destoante do debate sobre o branqueamento que ocorria no período 9 (SEYFERTH, 1989).

Posterior a esse debate fundado no biológico, que, por sua vez, alicerçou a teoria do branqueamento, surge uma compreensão de certa forma mais crítica, que denunciava em alguma medida o racismo existente nas teorias anteriores, mas que inevitavelmente cai na armadilha do projeto civilizador. Ou seja, figuras como Manuel Bomfim não empregam o racismo explícito, mas passa a elencar a educação como instrumento civilizatório, que posteriormente foi somado a ele o da saúde pública, tão visivelmente identificado em Monteiro Lobato, por exemplo. Ressalta-se que nessa leitura sobre a questão racial o biológico foi abandonado, mas análises psíquicas foram incorporadas: tratou de forma implícita os não brancos como instáveis, imprevidentes, preguiçosos e fracos moralmente.

Neste sentido, percebe-se que o racismo ganhou particularidade, pois passou-se a entender uma possibilidade de superar o problema negro a partir do cruzamento, afastando-se de certa forma de algumas compreensões racistas da Europa (SKIDMORE, 1993). Essa perspectiva teve como reforço ideológico, o mito das três raças. Somado a isso, ainda se consolidou a ideia de não haver racismo no Brasil, pois desde o início do século XVIII já se produzia ensaios sobre uma suposta relação harmônica entre o senhor e o escravizado, como é possível encontrar em Santos (2014). Mas é certamente em Casa-

\footnotetext{
${ }^{9}$ A maior parte dos autores que discutiam a formação social brasileira já haviam abandonado as teorias racialistas pautadas no determinismo biológico, ou seja, acontecia certo consenso de que o atraso da população negra era em razão da sua cultura não civilizada. Mas, os defensores de Nina Rodrigues estavam tentando revitalizar essas teorias, por isso foram destoantes.
}

Temporalis, Brasília (DF), ano 19, n. 37, p. 26-44, jan./jun. 2019. | ISSN 2238-1856 
Grande \& Senzala, com Gilberto Freyre, que essa compreensão é de fato solidificada, onde também a democracia racial se petrifica como conceito.

Para fazer uma necessária ponderação é preciso dizer que

\begin{abstract}
Gilberto Freyre não construiu na sua obra uma visão propriamente idílica das relações senhor/escravo e, em grande parte, contrariou a elite comprometida com as teorias de determinismo racial, atingindo especialmente Oliveira Vianna. O impacto de 'Casa Grande e Senzala' foi considerável, inclusive no exterior, mas se por um lado pode ser considerado como principal marco de reação ao racismo no nosso meio acadêmico, por outro lado, o modo como interpreta as relações raciais tornou-se também a origem do ideário da democracia racial - embora não fosse porta-voz isolado dessa posição na década em que foi publicado (SEYFERTH, 1989, p. 21)
\end{abstract}

Em resumo, o mito da democracia racial, expressão cunhada por Florestan Fernandes (2008), é a compreensão de que no Brasil o problema racial foi revolvido pela miscigenação. Portanto, todas as desigualdades sociais que afligem as pessoas negras têm relação direta com o passado escravista. As discriminações, portanto, se relacionam apenas a questões de saúde, de educação etc. Ou seja, resolveu-se o problema das várias etnias porque se misturaram. Assim, a negação do racismo científico passou pela consolidação de outra estrutura racista perversa e resistente: a suposta igualdade racial. Essa foi fortemente moldada pela comparação com o racismo existente nos Estados Unidos da América (EUA).

Houve com isso, na tentativa de negar o racismo, uma retomada da Antropologia Cultural, retornando às leituras de Nina Rodrigues, com objetivos de encontrar a participação do negro na formação cultural do país. Contudo, essa busca servia na verdade para negá-la. Arthur Ramos, por exemplo, não foge das concepções evolucionistas. As compreensões fundadas no biológico se esvaem, contudo, aloca-se o negro a um lugar de cultura inferior à dos brancos, uma cultura atrasada. Neste sentido, aos poucos o racismo baseado unicamente no biológico deixa as compreensões do pensamento social brasileiro, tomando forma um novo, que somava cruzamento e caldeamento cultural, que era traduzida por uma ascensão social do mestiço, podendo ser percebido dos trabalhos de Gilberto Freyre (1933), de Donald Pierson (1942), de Thales de Azevedo (1955) etc.

Essas abordagens foram visivelmente influenciadas por Gilberto Freyre, como algumas outras produções do período. Existia nela a presença de mitos como o da relação afetiva senhor/escravo, produto da construção de relações cordiais entre ambos, o que por sua vez permitiu que o mestiço tivesse em alguma medida ascensão social.

A obra de Donald Pierson ganha grande relevância em nível de Brasil e até mundial. Esse autor era sociólogo, da Escola de Chicago, e assegurou que no Brasil não existia uma categorização racial. A discriminação estava restrita ao nível socioeconômico e educacional, e as desigualdades eram produto da própria competição entre indivíduos livres. Portanto, a condição social em que estavam as pessoas negras se relacionava com o passado de escravização dos seus ascendentes (SANTOS, 2014).

A partir dos idos dos anos de 1940, ampliam-se investigações sobre a questão racial no Brasil. Foi quando surgiram figuras importantes como Abdias do Nascimento (1914 - 2011)

Temporalis, Brasília (DF), ano 19, n. 37, p. 26-44, jan./jun. 2019. | ISSN 2238-1856 


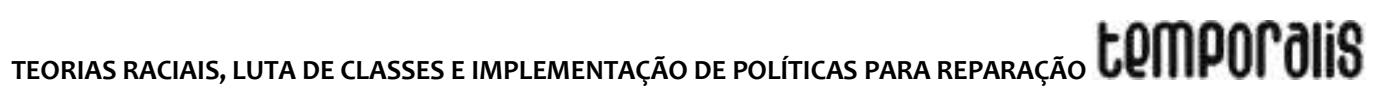

e Guerreiro Ramos (1915 - 1982), ambos concentraram suas atenções e produções intelectuais e artísticas para confrontar o que se produzia de científico naquele momento sobre a questão racial. Questionavam antropólogos e sociólogos, denunciando a existência do preconceito de cor e da discriminação racial, que, por sua vez, eram invisibilizadas pela produção corrente. É nesse interim que surge, mais uma vez a figura de Édison Carneiro fazendo contraposição às denúncias contra a discriminação. Argumentou que esse tipo de compreensão na verdade era uma apropriação de ideias externas, dos EUA, e o que esses intelectuais e militantes estavam praticando era na verdade um racismo às avessas.

Por fim, é na década de 1950, com a pesquisa da UNESCO, que os estudos sobre as relações raciais passam a ser objeto de pesquisa. O objetivo inicial desse trabalho era encontrar a explicação sobre o paraíso racial tratado por Gilberto Freyre, a fim de apresentá-lo ao mundo como exemplo a ser implantado por outros países que tinham em sua composição tal diversidade racial (HASENBALG, 1996). Entretanto, essa imagem criada por Freyre não foi deveras encontrada pelos pesquisadores.

Dentre os pesquisadores desse projeto, o mais importante, nessa compreensão, foi Florestan Fernandes. Ele, vindo de origem pobre, e tendo convivido com pessoas negras desde a infância, nos cortiços, entendia que as pesquisas feitas outrora por Bastide, seu professor, não correspondiam com a realidade da pessoa negra, e, portanto, esses trabalhos deveriam partir a uma linha que revelasse de fato a condição dessa população no Brasil. Assim, a hipótese de partida não deveria ser a de Nina Rodrigues, que apontava o Negro como um problema para o Brasil, mas sim, a de que o Brasil era um problema para o negro, onde sua cidadania plena era negada pelo simples fato dos seus traços negroides. Nessa perspectiva, buscava-se desmistificar o que chamou de o mito da democracia racial.

Florestan, afirma lanni (1996), foi o fundador da sociologia crítica no Brasil. Sob à luz da teoria marxista analisou e reviu conteúdos que estavam prevalecentes à época. Tratou a questão da população negra, por exemplo, como ainda não havia sido tratada. Isso foi possível, como já foi evidenciado, porque à luz do marxismo e, portanto, do método "[...] questiona o real e o pensado, tanto os pontos de vista dos membros dos grupos e classes compreendidos na pesquisa como as interpretações elaboradas sobre eles [...]" (IANNI, 1996, p. 26).

O surgimento na obra de Florestan do conteúdo Marxista ocorre devido à impositiva realidade brasileira que se apresentava ao autor. Os conteúdos clássicos da sociologia que eram utilizados por Fernandes se mostraram insuficientes diante de tamanha complexidade do real. Ou seja, a "[...] anatomia das relações, processos e estruturas de dominação política e apropriação econômica que articulam as desigualdades e os antagonismos sociais, econômicos, políticos e culturais [...]” (IANNI, 1996, p. 27), impunham-se de tal modo que só o conteúdo marxista possibilitou maior compreensão.

Diante dessa exposição teórica apresentada até aqui é possível dizer que a produção feita sobre a questão racial no Brasil, pelo pensamento social brasileiro, esteve fortemente relacionada com o processo de desenvolvimento econômico do país, mas ao mesmo tempo com um temor da classe branca dominante de que as pessoas negras pudessem se revoltar contra o regime escravista e tomar o poder, como foi em alguns lugares do mundo.

Temporalis, Brasília (DF), ano 19, n. 37, p. 26-44, jan./jun. 2019. | ISSN 2238-1856 
Com esse receio buscaram formas de eliminar a população negra, e as justificativas se basearam nas mais diversas teorias, como foram apresentadas.

\section{Movimento Negro: pauta negra}

O Movimento Negro brasileiro, como os demais movimentos contestatórios que existiam no país, sofreu significativo encolhimento com a instauração da ditadura civil militar de 1964. O debate que avançara até esse momento foi suprimido quase totalmente pelo regime. Tornou-se cada vez mais difícil aglutinar lideranças da pauta racial porque, inclusive, a questão racial foi elencada pelos militares como um elemento nocivo à segurança nacional, como é possível ler em Pereira (2011), Pereira (2008), Cardoso (2002); o debate sobre a questão racial era compreendido como importação de problemas, ou seja, não existia racismo no Brasil, afirmar isso seria inventar um problema que não dizia respeito ao país.

Leituras como essa, tão consolidada no imaginário social brasileiro, seguramente, é fruto da produção de conhecimento pautada numa realidade aparente, mas principalmente, forte investimento do Estado para a concretização daquilo que vinha se formando nas compreensões brasileiras desde o início do século XVIII, como já foi tratado no texto. E mais, compreensões arquitetadas por uma classe dominante que precisava produzir algo que posteriormente à mudança de regime, do de castas para o de classes, servisse como instrumento de manutenção da posição social construída no regime de escravização, como é possível ver em Florestan Fernandes (2008). Essa foi a razão, e nesse caso mais especificamente nas primeiras décadas do século XX, pela que o Estado, como instrumento da classe hegemônica, investiu fortemente na ideologia da democracia racial.

Mas, na dinâmica da história e, contraditoriamente, dentro do regime militar, e, evidentemente, como fruto do acúmulo histórico da produção de conhecimento e da luta dos movimentos negros e de resistência negra anterior, surge aquele que é tratado como uma das mais importantes organizações de Movimento Negro no Brasil, o MNU.

O salto qualitativo é compreendido por que o MNU além de se tornar um movimento político contestatório, passou a denunciar o racismo como elemento solidificado na formação social brasileira. E ainda, esse movimento também se colocou como uma estrutura que passou a perceber o próprio sistema capitalista como incompatível com a luta antirracista e, portanto, não reivindicavam mais a integração, denunciavam o racismo e a exclusão de classe, ou seja, o movimento negro passa a ter uma formação políticoideológica marxista, assim, passa a haver uma leitura sobre raça e classe (CARDOSO, 2002; PEREIRA, 2011; DOMINGUES, 2007).

Foi a partir do MNU que pautas mais contemporâneas foram incorporadas à racial. Esse movimento se estruturou de forma sistemática, realizando congressos onde se desenhava planos de ação contra o racismo. Um exemplo relevante do conteúdo desses documentos e da compreensão política deles é o Programa de Ação produzido no III Congresso Nacional da entidade, nele as discussões e deliberações giraram entorno de lutar Por uma autêntica democracia racial; contra a Marginalização do Negro; contra a Discriminação racial no trabalho; contra o Desemprego; por melhores Condições de vida; pelo Direito e contra a 


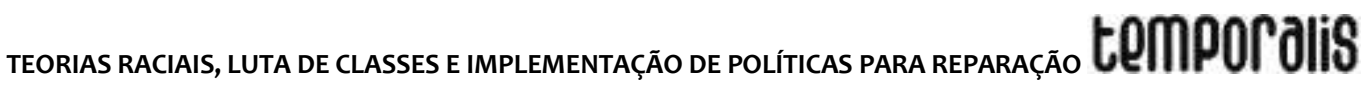

Violação; discutir as Prisões; discutir sobre O menor abandonado ${ }^{10}$; discutir a Cultura negra; discutir a Educação; discutir A mulher negra; produzir Imprensa negra; participação e organização dos Sindicatos e partidos políticos; discutir a Área rural; discutir as Posses de terras, doações e invasões; buscar a Introdução da história da África e do negro no Brasil nos currículos escolares; buscar articulação na Luta internacional contra o racismo; e buscar a Transformação geral da sociedade (CARDOSO, 2002; DOMINGUES, 2007).

Veja-se que houve de fato uma mudança significativa nas características e conteúdo da organização negra no país. O movimento passa a fazer mobilizações de massa, mesmo dentro da ditadura, movendo multidões em marcha contra o racismo e a violência racial. A tônica do movimento era o negro no poder. A palavra negro, que antes era vista de forma pejorativa, passa a ser ressignificada e utilizada como símbolo de orgulho e de resistência. Diz-se, portanto, de transformações significativas, contudo, foi no campo educacional e relativo à propriedade territorial que o movimento negro conseguiu êxito mais expressivo.

A partir do MNU o Movimento Negro como um todo passa a compreender as articulações com os partidos como uma forma relevante para se conquistar políticas públicas para a população negra. E essa movimentação junto com os partidos acontece, evidente, sem perder de vista os movimentos de ação direta, veja-se a Marcha Zumbi dos Palmares, de 1995 .

Esses elementos foram importantes e é possível perceber historicamente, inclusive, que foi principalmente com a chegada do Partido dos Trabalhadores ao executivo nacional que bandeiras como a educacional (especificamente sobre a questão racial) entraram na agenda estatal, além da pauta relacionada às comunidades quilombolas.

A lei 10.639/03, que versa sobre o ensino da história africana e brasileira nas escolas básicas, é um exemplo. Ela foi sancionada devido a compromissos assumidos ainda nas campanhas do partido, como aponta Pinotti (2016), mas a sua história tem uma trajetória bem particular. Ela começa nos idos da década de 1990, quando o PT era o único partido político que tinha uma Secretaria Nacional de Combate ao Racismo (SNCR), o que já demonstra articulação entre o partido e o movimento, pois em sua fundação, existia no PT uma comissão própria de negros, voltados à essa pauta. Esse detalhe é relevante por que sempre existiram parlamentares ligados ao movimento social civil negro, embora o MN tivesse ainda pouco poder de barganha dentro do congresso. Tanto que foi apresentada em meados da década uma proposta que instituía a criação de uma disciplina na educação básica voltada ao ensino da história e da cultura africana e afro-brasileira. Contudo, devida inclusive a restrições formais não obteve sucesso (PINOTTI, 2016).

Mas em março de 1999, apresentou-se ao congresso o projeto de lei 10.639, contudo, devido ao baixo poder de barganha dentro do legislativo a proposta circulou durante quatro anos, mas sem nenhum sucesso para se tornar lei. Entretanto, com a chegada do PT à presidência nacional, a lei foi aprovada em oito dias depois da posse (PINOTTI, 2016). Contudo, é evidente que essa lei foi aprovada, mas não sem ressalvas. A principal delas foi a falta de explicitação de como seriam as capacitações dos professores para ministrarem o

\footnotetext{
${ }^{10}$ Esse termo não é mais utilizado para se referir a crianças e/ou a adolescentes.
}

Temporalis, Brasília (DF), ano 19, n. 37, p. 26-44, jan./jun. 2019. | ISSN 2238-1856 
conteúdo, uma vez que a própria formação acadêmica superior não lhes garantia de fato esse conhecimento.

A outra política que foi estabelecida na alçada do primeiro governo petista foi o "[...] decreto $4887 / 2003^{11}$, que regulamenta o procedimento para identificação, reconhecimento, delimitação, demarcação e titulação das terras ocupadas por remanescentes das comunidades quilombolas" (RADOMYSLER, 2013, p. 33). Nessa, há, mais uma vez, uma mudança significativa na forma de atuação da luta do MN. Passa-se a perceber o Superior Tribunal Federal (STF) como espaço de trâmite e articulação política, como é possível perceber de maneira bem nítida em Radomysler (2013).

Diante do decreto presidencial 4887/2003, o partido Democrata (DEM) aciona a justiça com uma Ação Direta de Inconstitucionalidade (ADI), número 3239. Isso levou as entidades do MN a entrarem no processo como aminici curiae (amigos da corte), contudo, não se limitaram a fazer simplesmente oposição aos argumentos dos democratas, relataram as situações de exposição a riscos e não acesso a direitos básicos às quais comunidades quilombolas estavam expostas; expuseram a pequena quantidade de titulações que haviam ocorrido até a presente data, além de reafirmarem a obrigação do Estado em relação àquelas pessoas (RADOMYSLER, 2013).

Ações como essas levaram o MN a começar um processo, via audiência pública e articulações dentro do judiciário, de educação antirracista dentro do STF. Em entrevista a Radomysler (2013, p. 37), Frei Davi indica essa compreensão. Diz ele "[...] a audiência pública é fundamental, não só para os ministros, em nossa opinião, mas para a sociedade civil. Para a sociedade como um todo porque a imprensa foi obrigada a discutir, a apresentar o debate".

Mas essa não fora a única forma de atuação junto ao judiciário, conforme Radomysler (2013),

Outro recurso utilizado para enfrentar as dificuldades e fortalecer o uso do Judiciário [...], conforme narra Daniel Teixeira, coordenador de projetos do Centro de Estudos das Relações de Trabalho e Desigualdades (CEERT), é a capacitação realizada pela entidade de profissionais e acadêmicos sobre Direito de Igualdade Racial. Além de uma grande produção teórica sobre o assunto, o CEERT realiza um curso à distância e organiza um sítio eletrônico com todas as decisões disponíveis de diversos tribunais do Brasil que envolvam a temática racial (RADOMYSLER, 2013, p. 38).

E ainda,

Aline Lopes, da Assessoria Jurídica Mariana Criola, conta que houve uma articulação nacional da Rede de Advogados Populares para que movimentos sociais e outras organizações entrassem como amicus curiae na ADI 3239. Da mesma forma, Natália Machado, do Nosso Coletivo Negro, afirma terem insistido para que entidades de peso, como a Fundação Nacional dos Índios (FUNAI) e a Ordem dos Advogados do Brasil (OAB), entrassem na ADPF 186 como amicus curiae (RADOMYSLER, 2013, p. 39).

\footnotetext{
${ }^{11}$ Observe-se que se trata de uma regulamentação de lei que já havia sido elaborada no contexto da articulação do MN nacional junto à constituinte, onde se estabeleceu o direito das comunidades quilombolas aos seus territórios.
}

Temporalis, Brasília (DF), ano 19, n. 37, p. 26-44, jan./jun. 2019. | ISSN 2238-1856 


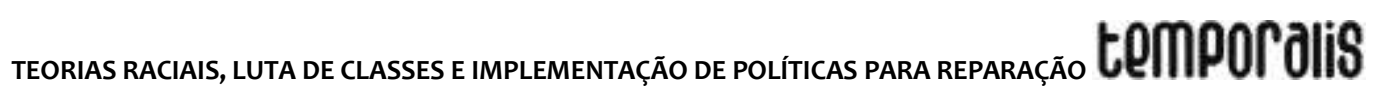

Diante dessas experiências observadas pela pesquisa do Radomysler, é possível perceber é como as formas e os espaços de atuação do $M N$ se modificaram de acordo com o processo histórico. E da mesma forma é possível ver que a dinâmica dos movimentos sociais em articulação com os partidos políticos implicou mudanças significativas em políticas voltadas à população negra do país, ainda que algumas sejam materializadas incompletamente, ou seja, se estabeleçam de uma forma na letra da lei e de outra na realidade prática. Isso indica, na verdade, a necessidade da permanente movimentação das organizações no que tange à materialização de políticas públicas voltadas à população negra, ainda que essas não sejam de fato o horizonte almejado, que seria a transformação radical da sociedade.

Por fim, um MN que ressurgiu ainda na década de 1970, durante a ditadura militar, com pautas articuladas com as demandas da população negra e mesmo com as demais que estavam sendo tratadas naquele momento pelos demais movimentos, consegue dado o novo perfil, articulação e disputa de políticas públicas no âmbito do Estado, obter significativo sucesso no decorrer dos anos e das disputas que travou junto às forças políticas contrárias.

\section{Considerações finais}

A história de luta e de resistência das pessoas negras no Brasil é uma história de luta de classes. Ela começou nesse país ainda no início do período colonial. As formas de enfrentar as diversas violências e exploração foram diversas, cada uma ligada à dinâmica e à particularidade sócio-histórica de cada região, fazenda ou lugarejo, contudo, é importante não perder de vista que todas elas estão inseridas e influenciadas diretamente com o processo de desenvolvimento mundial do capitalismo. Mesmo o país sendo uma colônia, estava ligado a essa dinâmica.

Assim, tento isso como estrutural, buscou-se analisar a trajetória histórica do movimento negro, principalmente do final do século XIX até o início do XXI, apresentando que concomitante ao desenvolvimento das organizações e dos movimentos negros foi produzido conteúdo significativo sobre uma questão que surgia, a questão racial, e que passou a ocupar espaço significativo no pensamento social brasileiro, ora para apresentála como problema a ser extirpado, noutra para negá-la, e, por fim, como uma questão a ser enfrentada. E foi no bojo dessas movimentações, debates e disputas, que a pauta racial passou em certa medida a integrar a agenda oficial brasileira.

As principais marcações históricas relativas aos movimentos, é possível dizer que foram as organizações que ainda não eram movimentos (jornais, clubes e associações), a Frente Negra Brasileira, a UHC e o TEN, e por fim o MNU. Todos tinham nitidez de que as condições de vida da população negra estavam em grande medida relacionadas à cor da pele, contudo, cada um reagiu a isso de acordo com o próprio momento histórico e as condições objetivas de sua época.

Cabe refletir que esses movimentos foram criados ao mesmo tempo em que se produzia forte conteúdo racialista. Cada movimento foi diretamente implicado por essas leituras e só se pode de fato romper com as velhas compreensões adaptativas e integrativas do

Temporalis, Brasília (DF), ano 19, n. 37, p. 26-44, jan./jun. 2019. | ISSN 2238-1856 
negro quando se tomou posse do conteúdo marxista. Foi então que o movimento ganha mais relevância e alcance. Incluindo já na constituição de 1988 o direito das comunidades quilombolas às suas terras. Adiante finalmente se aprova a lei 10.639/03, que obriga o ensino da história africana e da cultura afro-brasileira, bem como se estabelece o decreto que regulamento a titulação das terras dos quilombos.

Todo o trajeto até aqui foi tratado como movimento. Um movimento ora desorganizado, mas que ganha mais significância no decorrer do processo histórico. Eles se moveram contra uma realidade sensível que Ihes afligia fortemente, as condições de vida, mas também contra um conteúdo ideológico produzido como ciência e que pretendeu justificar as condições as quais eram submetidos. Esse conteúdo é a raça/racismo. Foi defendido como científico e negado como forma de manter as estruturais sociais acomodadas e, por fim, revelado e tratado como uma mazela a ser enfrentada.

\section{Referências}

AZEVEDO, Thales de. As elites de cor, um estudo de ascensão social. São Paulo: Cia. Editora Nacional, 1955.

BAHIA, Joana; MENASCHE, Renata; ZANINI, Maria Catarina Chitolina (Org.). Pensamento social no Brasil, por Giralda Seyferth: notas de aula. Porto Alegre: Letra \&Vida, 2015. 256p. Disponível em: https://scholar.google.com.br/scholar?hl=pt-

BR\&as_sdt $=0 \% 2 C 5 \& q=$ Pensamento + social+no+Brasil $\% 2 C+$ por+Giralda+Seyferth\%3A+notas +de+aula.\&btnG. Acesso em: 27 dez. 2017.

CARDOSO, Marcos. O Movimento Negro em Belo Horizonte. Belo Horizonte: Mazza Edições, 2002.

CARNEIRO, Édison. Ladinos e crioulos. Rio de Janeiro: Civilização Brasileira, 1964.

CUNHA JR., Henrique. Textos para o movimento negro. São Paulo: Edicon, 1992.

DOMINGUES, Petrônio. Movimento negro brasileiro: alguns apontamentos

históricos. Tempo, Niterói, v. 12, n. 23, 2007. Disponível em:

http://www.scielo.br/scielo.php?script=sci_arttext\&pid=S1413-

77042007000200007\&lng=pt\&nrm=iso. Acesso em: 1 dez. 2017.

DOMINGUES, Petrônio. Um "templo de luz": Frente Negra Brasileira (1931-1937) e a questão da educação. Revista Brasileira de Educação, Rio de Janeiro, v. 13, n. 39, 2008. Disponível em: http://www.scielo.br/scielo.php?script=sci_arttext\&pid=S141324782008000300008\&lng=pt\&nrm=iso. Acesso em: 1 dez. 2017.

FERNANDES, Florestan. A Integração do Negro na Sociedade de Classes: no limiar de uma nova era. v. 2. São Paulo: Globo, 2008.

FRY, Peter. A persistência da raça: ensaios antropológicos sobre o Brasil e a África austral. Rio de Janeiro: Civilização Brasileira, 2005. 350 p. Resenha de: SCHWARCZ, Lilia Moritz. Horizontes Antropológicos, Porto Alegre, v. 12, n. 25. 2006. Disponível em: 


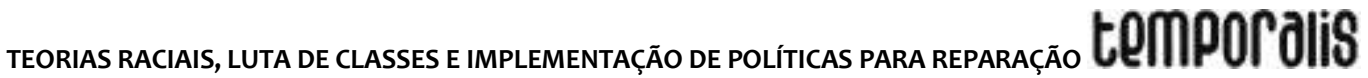

http://www.scielo.br/scielo.php?script=sci_arttext\&pid=S0104-71832006000100015. Acesso em: 1 dez. 2017.

FREYRE, Gilberto. Casa-Grande \& senzala. São Paulo: Global, 2006.

HASENBALG, Carlos Alfredo. Entre o mito e os fatos: racismo e relações raciais no Brasil. In: MAIO, Marcos Chor; VENTURA, Ricardo (Org.). Raça, ciência e sociedade. Rio de Janeiro: Fiocruz, 1996. p. 235-249.

IANNI, Octávio. A sociologia de Florestan Fernandes. Estudos avançados, São Paulo, v. 10, n. 26, p. 25-33, 1996. Disponível em:

http://www.scielo.br/scielo.php?script=sci_arttext\&pid=S0103-

40141996000100006\&lng=en\&nrm=iso. Acesso em: 1 dez. 2017.

MAIO, Marcos Chor; SANTOS, Ricardo Ventura. O espetáculo das raças: cientistas, instituições e questão racial no Brasil, 1870-1930. História, Ciências, Saúde-Manguinhos, Rio de Janeiro, v. 1, n. 1, p. 173-175, 1994.

MARX, Karl; ENGELS, Friedrich. Manifesto do partido comunista. São Paulo: Edipro, 1998. 112p. (Série clássicos).

MARQUESE, Rafael de Bivar. A dinâmica da escravidão no Brasil: resistência, tráfico negreiro e alforrias, séculos XVII a XIX. Novos estudos-CEBRAP, São Paulo, n. 74, p. 107123, 2006. Disponível em: http://www.scielo.br/scielo.php?script=sci_arttext\&pid=S0101$33002006000100007 \&$ Ing=en\&nrm=iso. Acesso em: 1 dez. 2017.

MOURA, Clovis. Quilombos: resistência ao escravismo. 2. ed. São Paulo: Ática, 1989. 94p.

MULLER, Liane S. As contas do meu rosário são balas de artilharia: irmandade, jornal e associações negras em Porto Alegre (1889-1920). Dissertação (Mestrado em História)IFCH/Pontifícia Universidade Católica do Riogrande do Sul, Porto Alegre, 1999.

MUNANGA, Kabengele. Teoria social e relações raciais no Brasil contemporâneo. Especial Curso ERER-Educação para as Relações Étnico-raciais. Caderno PENESB, Niterói, n. 12, 2010.

NASCIMENTO, Washington Santos. "São Domingos, o grande São Domingos": repercussões e representações da Revolução Haitiana no Brasil escravista (17911840). Dimensões, n. 21, 2008.

NETTO, José Paulo. Ditadura e serviço social: uma análise do serviço social no Brasil pós64. 10. ed São Paulo: Cortez, 2007. 334 p.

ODA, Ana Maria Galdini Raimundo. Escravidão e nostalgia no Brasil: o banzo. Revista Latinoamericana de Psicopatologia Fundamental, São Paulo, 2008. Disponível em: http://www.redalyc.org/articulo.oa?id=233020554003. Acesso em: 8 dez. 2017.

Temporalis, Brasília (DF), ano 19, n. 37, p. 26-44, jan./jun. 2019. | ISSN 2238-1856 
OLIVEIRA, Laiana Lannes de. A Frente Negra Brasileira: política e questão racial nos anos 1930. 2002. Dissertação (Mestrado em História Política) - Programa de Pós-Graduação em História, Universidade do Estado do Rio de Janeiro, Rio de Janeiro, 2002.

PIERSON, Donald. Negroes in Brazil: a study of race contact in Bahia. Chicago, University of Chicago Press, 1942.

PEREIRA, Amilcar Araújo. Influências externas, circulação de referenciais e a constituição do movimento negro contemporâneo no Brasil: idas e vindas no "Atlântico Negro”. Ciências e Letras, Porto Alegre, n. 44, p. 215-236, 2008. Disponível em: https://scholar.google.com.br/scholar?hl=pt-

BR\&as_sdt $=0 \% 2 C 5 \& \mathrm{q}=$ Influ $\%$ C $3 \% A A n c i a s+$ externas $\% 2 C+$ circula $\% C_{3} \% A 7 \% C_{3} \% A 30+$ de + referen ciais+e+a+constitui $\% \mathrm{C}_{3} \% \mathrm{~A} 7 \% \mathrm{C} 3 \% \mathrm{~A} 30+$ do+movimento+negro+contempor $\% \mathrm{C}_{3} \% \mathrm{~A} 2$ neo + no $+\mathrm{B}$ rasil\%3A+idas+e+vindas+no+\%E2\%80\%9CAtl\%C3\%A2ntico+negro\%E2\%80\%9D\&btnG=. Acesso: 1 dez. 2017.

PEREIRA, Amilcar Araújo. Movimento negro brasileiro: aspectos da luta por educação e pela "reavaliação do papel do negro na história do Brasil" ao longo do século XX. In: SIMPÓSIO NACIONAL DE HISTÓRIA - ANPUH, 26., 2011, São Paulo. [Anais...]. São Paulo, jul. 2011. Disponível em: http://www.snh2011.anpuh.org/site/anaiscomplementares. Acesso em: 27 dez. 2017.

PINOTTI, Melina Lima. O Movimento Negro e a configuração da lei 10.639/03. In: ENCONTRO REGIONAL DE HISTÓRIA, 12., 2016. Coxim (MG). [Anais...]. nov. 2016. Disponível em: http://www.encontro2016.ms.anpuh.org/site/anaiscomplementares. Acesso: 27 dez. 2017.

PINTO, Regina Pahim. O movimento negro em São Paulo: luta e identidade. 1993. Tese (Doutorado)-FLCH-USP, São Paulo, 1993.

RAMOS, Alberto Guerreiro. Introdução crítica à sociologia brasileira. Rio de Janeiro: Andes, 1957.

RADOMYSLER, Clio Nudel. STF: um espaço de luta do movimento negro. Rio de Janeiro, Direito e Praxis, v. 4, n. 6, 2013, pp. 31-51. Disponível em: http://www.redalyc.org/articulo.oa?id=350944517003. Acesso: 27 dez. 2017.

REIS, João José. “Nos achamos em campo a tratar da liberdade": a resistência escrava no brasil oitocentista. Viagem incompleta: a experiência brasileira (1500-2000). Formação: histórias. São Paulo: Editora do Senac, p. 241-263, 2000.

ROMERO, Silvio. História da literatura brasileira. Rio de Janeiro: J. Olympio, 2001.

SANTOS, Sérgio Pereira dos. Os 'intrusos' e os 'outros' quebrando o aquário e mudando os horizontes: as relações de raça e classe na implementação das cotas sociais no processo seletivo para cursos de graduação da UFES - 2006-2012. 2014. 390 f. Tese (Doutorado em Educação) - Programa de Pós-Graduação em Educação, Universidade Federal do Espírito Santo, Vitória, 2014. 
SCHWARCZ, Lilia Moritz. O espetáculo das raças: cientistas, instituições e questão racial no Brasil, 1870-1930. São Paulo: Companhia das Letras, 2017 [1993].

SCHWARCZ, Lilia Moritz. A persistência da raça: ensaios antropológicos sobre o Brasil e a África austral. Horiz. antropol., Porto Alegre, v. 12, n. 25, p. 287-292, junho de 2006. Doi: http://dx.doi.org/10.1590/S0104-71832006000100015. Disponível em:

http://www.scielo.br/scielo.php?script=sci_arttext\&pid=S010471832006000100015\&lng=en\&nrm=iso. Acesso em: 28 dez. 2017.

SEYFERTH, Giralda. As ciências sociais no Brasil e a questão racial. Cativeiro e liberdade: seminário do Instituto de Filosofia e Ciências Humanas da Universidade do Estado do Rio de Janeiro, Rio de Janeiro: Cativeiro \& Liberdade, 1989.

SIMAS, Tatiany de Oliveira. Transgressões escravas no recife oitocentista: a resistência cotidiana 1837-1840. Cadernos Imbondeiro, João Pessoa, v. 3, n. 2, 2014. Disponível em: http://periodicos.ufpb.br/ojs2/index.php/ci/issue/view/1479>. Acesso em: 1 dez. 2017.

SKIDMORE, Thomas. White into black Durham e Londres: Duke University Press, 1993.

\footnotetext{
Jônatas Corrêa Nery elaboração do artigo resultado da avaliação parcial de uma disciplina do curso de mestrado em Política Social

Possui Graduação (Bacharelado) em Ciências Econômicas, é Mestrando do Programa de Pós-graduação em Política Social (PPGPS) e Graduando do curso de Serviço Social, ambos pela Universidade Federal do Espírito Santo (UFES). Faz parte do Núcleo de Estudos, Pesquisa e Extensão, sobre Violência, Direitos Humanos e Segurança Pública (NEVI-UFES) e é coordenador de comunicação do Movimento Nacional Quilombo Raça e Classe - ES (QRC - ES).

Rogério Naques Faleiros participou na indicação de leituras, formatação e adequação formal e teórica.

Possui Graduação (Bacharelado e Licenciatura) em História pela Universidade Estadual Paulista (1999), Mestrado em História Econômica (2002) e doutorado (2007) em Economia Aplicada (área de concentração em História Econômica), ambos pelo Instituto de Economia da Universidade Estadual de Campinas (UNICAMP). Atualmente é Professor Associado II do Departamento de Economia da Universidade Federal do Espírito Santo (UFES) e do Programa de Pós-Graduação em Política Social, exercendo também o cargo de Diretor do Centro de Ciências Jurídicas e Econômicas CCJE-UFES (2013/2017 e 2017/2021).
}

Temporalis, Brasília (DF), ano 19, n. 37, p. 26-44, jan./jun. 2019. | ISSN 2238-1856 